\title{
Deficiency of long-chain polyunsaturated fatty acids in phenylketonuria: a cross-sectional study
}

\author{
Sławomira Drzymała-Czyż ${ }^{1 凶}$, Łukasz Kałużny¹, Patrycja Krzyżanowska-Jankowska1, Dariusz \\ Walkowiak², Renata Mozrzymas ${ }^{3}$ and Jarosław Walkowiak ${ }^{1}$
}

'Department of Pediatric Gastroenterology and Metabolic Diseases, Poznan University of Medical Sciences, Poznań, Poland; ${ }^{2}$ Department of Organization and Management in Health Care, Poznan University of Medical Sciences, Poznań, Poland; 3Voivodeship Hospital, Wrocław, Poland

The etiology of altered blood fatty acid (FA) profile in phenylketonuria (PKU) is understood only partially. We aimed to determine whether FAs deficiency is dependent on the diet or metabolic disturbances. The study comprised 40 PKU patients (20 female, 20 male; aged 11 to 35 years; 12 children and 28 adults) and 40 healthy subjects (HS; 20 female, 20 male, aged 18 to 33 years). We assessed the profile of FAs (gas chromatography/ mass spectrometry) and analyzed the 72-hour dietary recalls. The amount of C14:0, C16:0 and C16:1n-7, C18:1n-9 did not differ between the analyzed groups. The percentage of C18:0 was higher, while C20:3n-9, C18:2n-6, C20:2n-6, C20:4n-6, C22:4n-6, C22:5n-6 and C22:6n-3 was lower in PKU than in HS. However, C18:3n-6, C18:3n-3 and $n-6 / n-3$ ratio were higher in PKU patients. The C20:4n-6/C20:3n- 6 ratio (reaction catalyzed by $\Delta 5$ desaturase), the C22:5n-6/C22:4n-6 and the C22:6n-3/ C22:5n-3 ratio (both reactions catalyzed by $\Delta 6$ desaturase) were significantly lower in PKU patients. Therefore, the deficiency of long-chain polyunsaturated fatty acids in PKU patients may result not only from inadequate supply but also from metabolic disturbances.

Key words: phospholipids, docosahexaenoic acid, dietary intake, inborn error of metabolism, metabolic diseases, desaturase

Received: 02 February, 2018; revised: 04 May, 2018; accepted: 07 May, 2018; available on-line: 18 June, 2018

e-mail: slawomiradrzymala@wp.pl

Abbreviations: AA, arachidonic acid; ALA, a-linolenic acid; DHA docosahexaenoic acid; EPA, eicosapentaenoic acid; EER estimated energy requirement; FA, fatty acid; $H S$, healthy subjects; LA, linoleic acid; LCPUFA, long-chain polyunsaturated fatty acids; MUFA, monounsaturated fatty acids; PKU, Phenylketonuria; $\mathrm{PAH}$, phenylalanine hydroxylase; Phe, phenylalanine; ROS, Rostock-Oseretzky Scale; SFA, saturated fatty acids; VEP, visually evoked potentials

\section{INTRODUCTION}

Phenylketonuria (PKU) is the most frequent inborn error of amino acid metabolism (Blau et al., 2011; Singh et al., 2016). A deficiency in phenylalanine hydroxylase $(\mathrm{PAH})$ activity leads to elevated levels of phenylalanine (Phe) in the blood. The signs and symptoms of untreated PKU comprise severe encephalopathy, mental retardation and neurological abnormalities, including seizures, microcephaly and other symptoms. Diagnosis by newborn screening and the implementation of a low-Phe diet in the neonatal period and beyond result in normal neurological and intellectual development in PKU patients (Blau et al., 2011; Scriver et al., 2001; Singh et al., 2016). In the low-Phe diet, $60-80 \%$ of the daily protein intake derives from a Phe-free L-amino acids mixture and $20-40 \%$ from fruit, vegetables and specially manu- factured low-protein products (Blau et al., 2010). The parents of PKU patients treated in our metabolic outpatient clinic analyzed the Phe, protein and energy intake of their children (as in most other European countries).

The PKU diet excludes meat and fish, which are natural sources of long-chain polyunsaturated fatty acids (PUFA) (Al Hafid \& Christodoulou, 2015; Singh et al., 2016). PUFA deficiency may negatively impact patients' psychomotor development and may induce metabolic imbalance, thus leading to changes in the fatty acids' (FA) profile (Al Hafid \& Christodoulou, 2015; Gramer et al., 2016; Schindeler et al., 2007). It should be noted that information on the relationship between the low-Phe diet and PUFA profile in PKU is contradictory (Acosta et al., 2001; Giovannini et al., 2011; Htun et al., 2015; Lage et al., 2010; van Gool CJ et al., 2000).

The aim of the study was to verify the hypothesis that the deficiency of specific FAs in PKU is dependent on either metabolic disturbances or the diet. This goal was achieved through the analysis of a larger number of FAs than in most studies which allowed us to investigate the desaturase activity in the context of dietary intakes.

\section{MATERIALS AND METHODS}

Patients. The study comprised 40 PKU patients (20 female, 20 male; aged 11 to 35 years; 12 children and 28 adults). The inclusion criteria were: PKU diagnosed by newborn screening and confirmed by biochemical testing, under regular control in an outpatient clinic, the reliable use of a low-Phe diet (good compliance), good general status and a willingness to participate in the study. The exclusion criteria were: elevated Phe levels during the previous 3 months (defined according to the recommendations - Phe concentration in the serum above $600 \mu \mathrm{mol} / \mathrm{L}$; van Wegberg et al., 2017); the presence of comorbidities (e.g., chronic gastrointestinal diseases or inflammatory processes, such as tonsillitis) and a family history positive for dyslipidaemia (hypercholesterolemia, hypertriglyceridemia), taking supplements enriched with FAs (e.g., blubber).

The control group consisted of 40 healthy subjects (HS; 20 female, 20 male, aged 18 to 33 years). Patients and HS were involved in the study in the years 2014 2015. All analyzes were performed in 2015/2016.

The anthropometric parameters describing PKU patients $(n=40)$ and HS $(n=40)$ are presented in Table 1.

Dietary intake. To estimate energy and macronutrient intake, subjects were asked to complete a 3-day diary (two working days and one during the weekend). The average content of energy, protein (Phe), lipids and carbohydrates in the daily food intake was calculated. The percentage of 
Table 1. Anthropometric parameters of phenylketonuria (PKU) patients and healthy subjects (HS)

\begin{tabular}{|c|c|c|c|}
\hline $\begin{array}{l}\text { Anthropometric parameters } \\
\text { Median } \\
\text { ( } 1 \text { st }-3^{\text {rd }} \text { quartiles) }\end{array}$ & PKU patients & HS & $p$ \\
\hline Age (years) & $\begin{array}{l}21.3 \\
(16.5-27.5)\end{array}$ & $\begin{array}{l}22.8 \\
(20.6-25.2)\end{array}$ & ns \\
\hline Z-score for body weight & $\begin{array}{l}0.31 \\
(-0.44-0.76)\end{array}$ & $\begin{array}{l}0.30 \\
(-0.81-0.87)\end{array}$ & ns \\
\hline Z-score for body height & $\begin{array}{l}-0.06 \\
(-0.37-0.32)\end{array}$ & $\begin{array}{l}0.01 \\
(-0.60-0.72)\end{array}$ & ns \\
\hline
\end{tabular}

ns, not significant

estimated daily energy requirements (EER) was calculated using Polish references for human nutrition (Jarosz, 2012). The analyses were performed with the use of Dietetyk 2015 software (Jumar, Poznań, Poland).

Additionally, the composition of all available PKU formulas was taken into consideration in order to determine FAs content (the results are presented in Supplementary Table A at www.actabp.pl).

Fatty acid analysis. Blood samples were collected after an overnight fasting period. Samples were centrifuged $\left(3000 \times \mathrm{g}, 10 \mathrm{~min}, 4^{\circ} \mathrm{C}\right)$, and stored in plastic vials at $-80^{\circ} \mathrm{C}$.

The profiles of the FAs were assessed using Glaser's method as we described previously (Drzymała-Czyż et al., 2017; Glaser et al., 2010). Individual fatty acid methyl esters were quantified by gas chromatography with mass spectrum (Agilent 7890 series II and 5975C, Agilent Technologies, Santa Clara, USA) using a BPX 70 column (BPX70, $25 \mathrm{~m} \times 0.22 \mathrm{~mm}$ ID $\times 0.25 \mu \mathrm{m}$, SGE Analytical Science, Ringwood, Australia) as described previously (Glaser et al., 2010). Peak integration was performed using MSD ChemStation (Agilent Technologies, Santa Clara, USA).

Statistical methods. The results of the analysis of the FAs were expressed as percentage values (\% wt/wt).
For all parameters, the medians and $1^{\text {st }}-3^{\text {rd }}$ quartiles were calculated. The Shapiro-Wilk test was used to check the normality of the data distribution. The Mann-Whitney U-test was used to assess the differences between the two groups (Tables 1 and 3). The correlations between daily FAs intake and their levels in serum were analyzed using Pearson's test. Values of $p<0.05$ were considered to be statistically significant. All statistical analyses were performed in Statistica 12.0 software environment (StatSoft, Inc., Tulsa, USA).

Ethical considerations. The protocol of the investigation was approved by the Ethical Committee of Poznań University of Medical Sciences, Poznań, Poland (decision no. 383/12). Written informed consent was obtained from the patients' parents and from patients who were 16-years-old or older. The study was carried out in accordance with the revised Declaration of Helsinki.

\section{RESULTS}

The consumption of protein, lipids and carbohydrates was balanced in both groups (Table 2). Daily energy intakes were adequate when compared to EERs.

Table 2. Dietary intakes in phenylketonuria (PKU) patients and healthy subjects (HS).

\begin{tabular}{|c|c|c|}
\hline \multirow{2}{*}{ Dietary intake } & PKU patients & $\mathrm{HS}$ \\
\hline & \multicolumn{2}{|l|}{$\begin{array}{l}\text { Median } \\
\left.\text { (1 } 1^{\text {st }}-3^{\text {rd }} \text { quartile }\right)\end{array}$} \\
\hline Energy (kcal/d) & $\begin{array}{l}1915 \\
(1471-2267)\end{array}$ & $\begin{array}{l}1882 \\
(1656-2303)\end{array}$ \\
\hline Estimated daily energy requirement (\%) & $\begin{array}{l}96.8 \\
(75.8-113.3)\end{array}$ & $\begin{array}{l}96.4 \\
(85.7-100.8)\end{array}$ \\
\hline Protein (\% en) & $\begin{array}{l}14.4 \\
(11.9-20.1)\end{array}$ & $\begin{array}{l}15.0 \\
(13.9-18.5)\end{array}$ \\
\hline Carbohydrates (\% en) & $\begin{array}{l}59.6^{*} \\
(49.1-63.5)\end{array}$ & $\begin{array}{l}49.4^{*} \\
(39.7-48.3)\end{array}$ \\
\hline Total fat (\% en) & $\begin{array}{l}26.8^{* *} \\
(22.1-30.8)\end{array}$ & $\begin{array}{l}35.6^{* *} \\
(32.3-39.9)\end{array}$ \\
\hline Saturated fat (\% en) & $\begin{array}{l}14.8 \\
(7.9-17.0)\end{array}$ & $\begin{array}{l}14.6 \\
(13.9-17.8)\end{array}$ \\
\hline Monounsaturated fat (\% en) & $\begin{array}{l}9.2^{* *} \\
(6.4-14.9)\end{array}$ & $\begin{array}{l}15.4^{* *} \\
(13.9-16.7)\end{array}$ \\
\hline Polyunsaturated fat (\% en) & $\begin{array}{l}2.8^{* *} \\
(1.6-5.6)\end{array}$ & $\begin{array}{l}5.6^{* *} \\
(4.4-6.7)\end{array}$ \\
\hline C18:2n-6 (\% en) & $\begin{array}{l}2.1^{* *} \\
(1.8-3.7)\end{array}$ & $\begin{array}{l}3.9 * * \\
(3.5-5.3)\end{array}$ \\
\hline C18:3n-3 (\% en) & $\begin{array}{l}0.6 \\
(0.4-0.8)\end{array}$ & $\begin{array}{l}0.7 \\
(0.6-0.9)\end{array}$ \\
\hline
\end{tabular}

Asterisks indicate statistical significance in comparison with the control group (HS; $\left.{ }^{*}<0.05 ;{ }^{* *}<0.01 ;{ }^{* * *}<0.001\right)$. 
It should be noted that the consumption of total lipids (including monounsaturated fat and polyunsaturated fat) was lower in PKU patients. The daily intake of C18:2n-6 (linoleic acid; LA) was insufficient in all the patients tested (less than the recommended $4 \%$ of total energy), while the supply of C18:3n-3 ( $\alpha$-linolenic acid; ALA) in the diet was sufficient in $61 \%$ of patients (more than the recommended $0.5 \%$ of total energy) (Jarosz, 2012). Almost half of the daily intake of LA and ALA came from PKU formulas (median $\left[1^{\text {st }}-3^{\text {rd }}\right.$ quartile]: 47.4\% [32.0-63.3] and 48.1\% [28.3-56.9], respectively). The fat content of PKU formulas available in Poland is presented in Supplementary Table A at www.actabp.pl. For comparison, the insufficient consumption of LA and ALA in the control group was noted only in $32 \%$ and $3 \%$ of subjects, respectively.

The profile of selected FAs in the serum glycerophospholipids of PKU patients and HS is shown in Table 3. The amounts of two saturated FAs (SFA; C14:0, C16:0) and two monounsaturated FAs (MUFA; C16:1n-7, C18:1n-9) did not differ between the groups in the study. The percentage of C18:0 was higher, while C20:3n-9 was lower in the group of PKU patients.

Table 3. The profile of selected fatty acids in phospholipids of phenylketonuria (PKU) patients' and healthy subjects' (HS) blood serum.

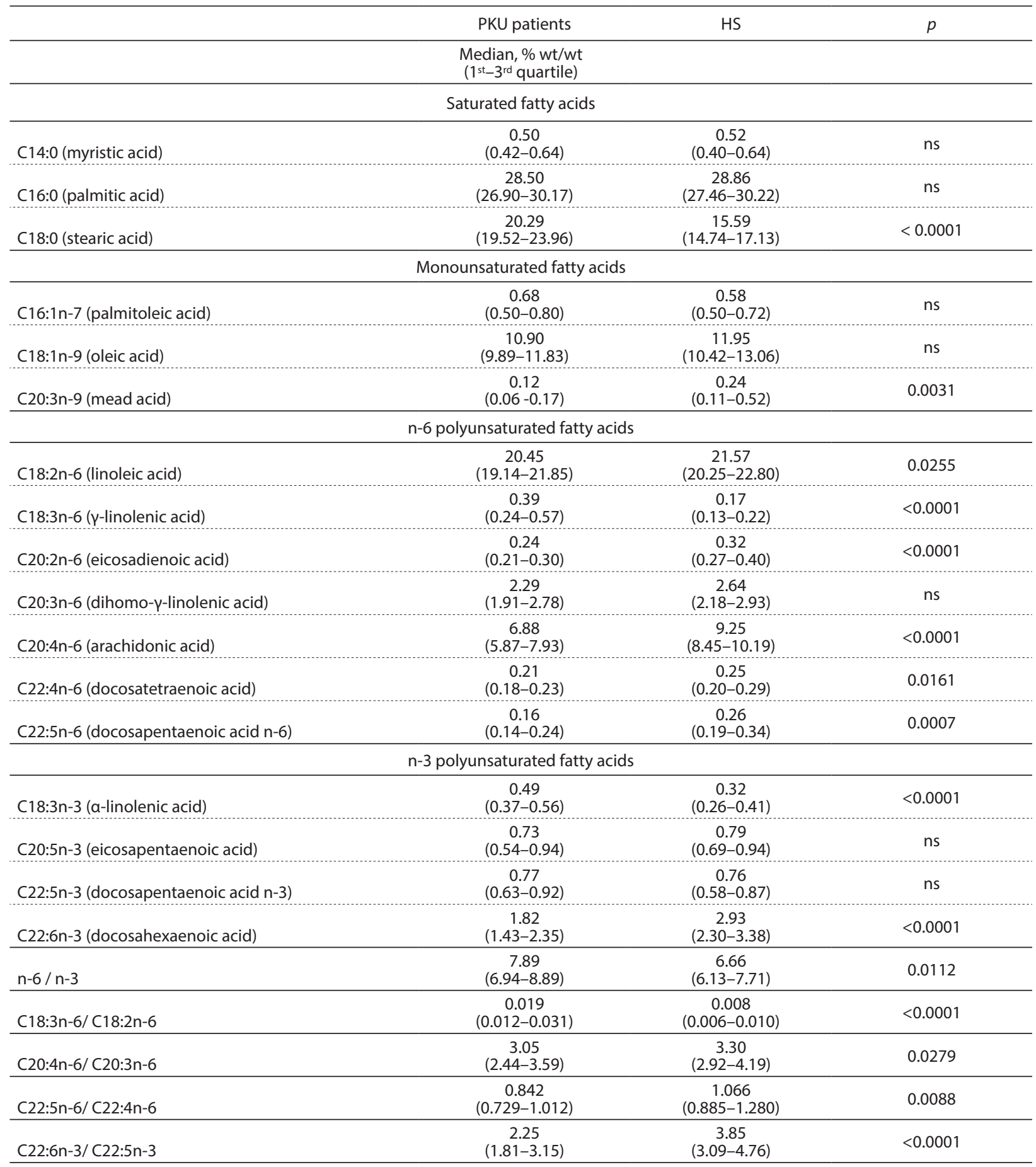

ns, not significant 
C18:2n-6, C20:2n-6, C20:4n-6, C22:4n-6, C22:5n-6 and C22:6n-3 were lower in the PKU group than in HS. However, C18:3n-6 and C18:3n-3 were higher in PKU patients. The $n-6 / n-3$ ratio was higher in the PKU group.

The C18:3n-6/C18:2n-6 ratio (reaction catalyzed by $\Delta 6$-desaturase) was significantly higher in PKU patients compared with HS. However, the C22:5n-6/C22:4n-6 and the C22:6n-3/C22:5n-3 ratio (both also catalyzed by $\Delta 6$-desaturase) were significantly lower in PKU patients, similarly as the C20:4n-6/C20:3n-6 ratio (reaction catalyzed by $\Delta 5$-desaturase).

No correlations between daily FAs intake and their serum levels were found (ns for all FAs).

\section{DISCUSSION}

We performed a comprehensive analysis of serum FA composition including 17 long-chain FAs in PKU patients adhering to the Phe-restricted diet, which revealed abnormalities in long-chain FAs. We documented that changes in the FA profile did not depend on the diet exclusively, but seemed to be also related to metabolic disturbances present in PKU.

The main aim of treating PKU is to keep the serum Phe levels within the recommended range. Brain damage prevention is the main reason for using a protein-, Pheand energy-balanced diet (Blau et al., 2011; Singh et al., 2016). The PKU-diet is a restrictive diet and, to some extent, resembles a vegan diet. According to the previous studies, vegan-like diets usually tend to be very poor sources of LCPUFAs. They result in poor LCPUFA status and docosahexaenoic acid (DHA) amounts in plasma and erythrocytes (Feillet \& Agostoni, 2010; Moseley et al., 2002). This may have negative consequences for the function of the central nervous system, especially in the first year of life. Therefore, it was necessary to implement the supplementation of LCPUFA in infancy by using special Phe-free formulas (Giovannini et al., 2012; Koletzko et al., 2007).

The beneficial effect of PUFA supplementation in PKU was described by Agostoni and coworkers (Agostoni et al., 2003) who found that the latency time in the P100 wave of visually evoked potentials (VEP) improves (decreases) in PKU children who are given eicosapentaenoic acid (EPA) and DHA. However, the effect was not durable and the parameter returned to its baseline value after three years (Agostoni et al., 2003). The authors suggested that the non-persistence of the effect of DHA supplementation could result from the small size of the research population $(n=10)$ and the relatively high intersubject variability. Koletzko and coworkers (Koletzko et al., 2009) analyzed plasma phospholipids FAs, VEP and motor skills by motometric function based on the Rostock-Oseretzky Scale (ROS). VEP and ROS significantly improved after 3 months of DHA supplementation (dose: $15 \mathrm{mg}$ DHA $/ \mathrm{kg}$ daily), which also resulted in increases in EPA and DHA plasma levels (Beblo et al., 2007; Koletzko et al., 2009). The Committee on $\mathrm{Nu}-$ trition of the European Society for Paediatric Gastroenterology, Hepatology and Nutrition (ESPGHAN) concluded that LCPUFA supplementation in PKU children older than 2 years, although feasible and safe, offers only transient benefits in the visual function (Agostoni et al., 2011).

The positive effects of PUFA supplementation are well documented. Unfortunately, despite this knowledge, too little attention is paid to it and PUFA deficiency is widespread. Lohner conducted a systematic review and a meta-analysis, which were based on 9 case-control studies and 6 randomized controlled trials, showing a poorer status of both EPA and DHA in PKU patients (Lohner et al., 2013). The failure to obtain optimal PUFA status was explained by the limited dietary intake. PUFA levels depended on the degree of restrictiveness of the diet used, especially in patients older than 2 years. It should be noted that formulas for older children do not provide a sufficient intake of FAs. A low level of arachidonic acid (AA) in total plasma lipids was also described - an observation consistent with our results. Likewise, newer research documented that plasma DHA levels in study subjects were significantly lower than in the control group (Bosdet et al., 2014). On the other hand, higher levels of EPA and ALA in subjects with PKU were found in that study. For this reason, the authors suggested that FAs should be supplemented with preformed DHA rather than with its precursors. In our study, a high percentage of ALA and a low of DHA were also reported.

We did not find any correlation between daily FAs intake and their serum levels. PUFAs intake did not affect their levels in a study by Gramer and coworkers either (Gramer et al., 2016). The authors noted that DHA levels were similar in patients consuming PKU formula with or without PUFA supplementation. This result can suggest that not only dietary but also metabolic disturbances lead to this FA deficiency.

The daily intake of C18:2n-6 (LA) and C18:3n-3 (ALA) should be $4 \%$ and $0.5 \%$ of the total energy, respectively (Jarosz, 2012). Assuming that the average energy intake was $2000 \mathrm{kcal}$ in our patients, the supply of LA should be $9.0 \mathrm{~g}$ and that of ALA $1.1 \mathrm{~g}$. If the patients had been on a PKU-diet and used PKU formulas in a "normal" (standard) dose, they would not consume a sufficient amount of the previously mentioned FAs. Therefore, it seems that the current composition of PKU formulasis insufficient in this respect. Even an extra $10 \mathrm{~g}$ of rapeseed oil (most commonly used in the Polish population) does not provide enough LA (such a portion would contain $1.7 \mathrm{~g} \mathrm{LA}$ and $0.8 \mathrm{~g}$ ALA). On the other hand, as we show in Supplementary Table A at www.actabp.pl, the data regarding formula composition are not complete and in many cases, the composition of the formula is not properly defined (different vegetable oils and fats used in different batches). Therefore, it is difficult to reliably assess the total intake of FAs in PKU.

In our study the following ratios were lower in PKU patients than in HS: C20:4n-6/C20:3n-6 (reaction catalyzed by $\Delta 5$-desaturase), C22:5n-6/C22:4n-6 and C22:6n-3/C22:5n-3 ratio (both: $\Delta 6$-desaturase); on the other hand the C18:3n-6/C18:2n-6 ratio (also $\Delta 6$ desaturase) was higher. This might indicate a lack of feedback inhibition of $\Delta 6$-desaturase by insufficient DHA (Calder, 2012). Our results were presented as percentages $(\%$ wt/wt), which allowed us to highlight the changes in the processing of FAs.

LA and ALA belong to essential fatty acids which cannot be synthesized in the human organism. However, these FAs are the precursors for AA and DHA. DHA is synthesized in two paths - microsomal-peroxisomal and mitochondrial (Infante \& Huszagh, 2001; Moore et al., 1995). In different tissue models, Phe and its metabolites inhibited the mitochondrial FA desaturase and the pathway of DHA synthesis (Infante \& Huszagh, 2001; Moore et al., 1995). Furthermore, it seems that this process may occur even in patients who use low-Phe diet 
recommendations (as in our study), because the PUFA levels are substantially lower in PKU patients than those of healthy individuals on vegetarian or similar vegetarian-type diets. Infante and Huszagh (Infante \& Huszagh, 2001) suggested that catabolic products of excess Phe (phenylpyruvate and phenylacetate) inhibit alpha-tocopherolquinone synthesis at the level of the deoxygenation reaction which leads to an impairment of DHA and AA synthesis in PKU. Schuck et al. found evidence for the inhibiting effect of Phe metabolites on PUFA synthesis as a potential reason for lipid disturbances (Schuck et al., 2015). In PKU patients total lipid metabolism seems to be impaired, as exemplified by low total cholesterol, high-density lipoprotein, low-density lipoprotein and apolipoprotein A-I/A-II and B. Studies in an animal model showed that these observations may be related to a decrease in expression of an enzyme regulating cholesterogenesis - 3-hydroxy-3-methylglutaryl coenzyme A reductase (Schuck et al., 2015; Shefer et al., 2000). It should be considered that in our study the levels of ALA were higher while DHA was lower and it was accompanied by similar changes in the ratios between the corresponding FAs. This confirms that in PKU patients endogenous synthesis of PUFA can be impaired.

In conclusion, we found that the deficiency of LCPUFAs in PKU patients may result not only from an insufficient supply but also from hitherto unknown PKUrelated metabolic disturbances. Further research on desaturases' activity in PKU is warranted.

\section{Conflicts of interest}

The authors report no conflicts of interest.

\section{Acknowledgments}

We are grateful to the phenylketonuria patients and their families for their cooperation.

SDC was a recipient of a fellowship from the NUTRICIA Research Foundation at the Division of Metabolic and Nutritional Medicine, Dr. von Hauner Children's Hospital, University of Munich Medical Centre, Munich, Germany. SDC would like to thank Dr Hans Demmelmair for his supervision during the fellowship and cooperation.

\section{Acknowledgments of Financial Support}

The study was supported by a grant from Poznań University of Medical Sciences (No 502-01-010311507588).

\section{REFERENCES}

Acosta PB, Yannicelli S, Singh R, Eisas LJ, Kennedy MJ, Bernstein L, Rohr F, Trahms C, Koch R, Breck J (2001) Intake and blood levels of fatty acids in treated patients with phenylketonuria. J Pediatr Gastroenterol Nutr 33: 253-259

Agostoni C, Braegger C, Decsi T, Kolacek S, Mihatsch W, Moreno LA, Puntis J, Shamir R, Szajewska H, Turck D, van Goudoever J (2011) Supplementation of N-3 LCPUFA to the diet of children older than 2 years: a commentary by the ESPGHAN Committee on nutrition. J Pediatr Gastroenterol Nutr 53: 2-10. https://doi. org/10.1097/MPG.0b013e318216f009

Agostoni C, Verduci E, Massetto N, Fiori L, Radaelli G, Riva E, Giovannini M (2003) Long term effects of long chain polyunsaturated fats in hyperphenylalaninemic children. Arch Dis Child 88: $582-583$

Al Hafid N, Christodoulou J (2015) Phenylketonuria: a review of current and future treatments. Transl Pediatr 4: 304-317. https://doi. org/10.3978/j.issn.2224-4336.2015.10.07

Beblo S, Reinhardt H, Demmelmair H, Muntau AC, Koletzko B (2007) Effect of fish oil supplementation on fatty acid status, coordination, and fine motor skills in children with phenylketonuria. I Pediatr 150: 479-484. https://doi.org/10.1016/j.jpeds.2006.12.011

Blau N, Bélanger-Quintana A, Demirkol M, Feillet F, Giovannini M, MacDonald A, Trefz FK, van Spronsen F, European PKU centers (2010) Management of phenylketonuria in Europe: survey results from 19 countries. Mol Genet Metab 99: 109-115. https://doi. org/10.1016/j.ymgme.2009.09.005

Blau N, Hennermann JB, Langenbeck U, Lichter-Konecki U, (2011) Diagnosis, classification, and genetics of phenylketonuria and tetrahydrobiopterin (BH4) deficiencies. Mol Genet Metab 104 (Suppl: S2S9). https://doi.org/10.1016/j.ymgme.2011.08.017

Bosdet T, Branov J, Selvage C, Yousefi M, Sirrs S (2015) Diet history is a reliable predictor of suboptimal docosahexaenoic acid levels in adult patients with phenylketonuria. JIMD Reports 21: 97-102

Calder PC (2012) Mechanisms of action of (n-3) fatty acids. J Nutr 142: 592S-599S. https://doi.org/10.3945/jn.111.155259

Drzymała-Czyż S, Krzyżanowska P, Koletzko B, Nowak J, MiśkiewiczChotnicka A, Moczko J, Lisowska A, Walkowiak J (2017) Determinants of serum glycerophospholipid fatty acids in cystic fibrosis. Int J Mol Sci 18: 185. https://doi.org/10.3390/ijms18010185

Feillet F, Agostoni C (2010) Nutritional issues in treating phenylketonuria. J Inherit Metab Dis 33: 659-664. https://doi.org/10.1007/ s10545-010-9043-4

Giovannini M, Verduci E, Radaelli G, Lammardo A, Minghetti D, Cagnoli G, Salvatici E, Riva E (2011) Long-chain polyunsaturated fatty acids profile in plasma phospholipids of hyperphenylalaninemic children on unrestricted diet. Prostaglandins Leukot Essent Fatty Acids 84: 39-42. https://doi.org/10.1016/j.plefa.2010.09.003

Giovannini M, Verduci E, Salvatici E, Paci S, Riva E (2012) Phenylketonuria: nutritional advances and challenges. Nutr Metab 9: 7. https://doi.org/10.1186/1743-7075-9-7

Glaser C, Demmelmair H, Koletzko B (2010) High-throughput analysis of fatty acid composition of plasma glycerophospholipids. J Lipid Res 51: 216-221. https://doi.org/10.1194/jlr.D000547

Gramer G, Haege G, Langhans CD, Schuhmann V, Burgard P, Hoffmann GF (2016) Long-chain polyunsaturated fatty acid status in children, adolescents and adults with phenylketonuria. Prostaglandins Leukot Essent Fat Acids 109: 52-57. https://doi.org/10.1016/j.plefa.2016.04.005

Htun P, Nee J, Ploeckinger U, Eder K, Geisler T, Gawaz M, Bocksch W, Fateh-Moghadam S (2015) Fish-free diet in patients with phenylketonuria is not associated with early atherosclerotic changes and enhanced platelet activation. PloS One 10: e0135930. https://doi. org/10.1371/journal.pone.0135930

Infante JP, Huszagh VA (2001) Impaired arachidonic (20:4n-6) and docosahexaenoic (22:6n-3) acid synthesis by phenylalanine metabolites as etiological factors in the neuropathology of phenylketonuria. Mol Genet Metab 72: 185-198. https://doi.org/10.1006/mgme.2001.3148

Jarosz M (2012) Nutrition standards for the Polish population. Instytut $\dot{Z}_{y}$ wności i Żywienia (in Polish)

Koletzko B, Beblo S, Demmelmair H, Müller-Felber W, Hanebutt F.L (2009) Does dietary DHA improve neural function in children? Observations in phenylketonuria. Prostaglandins Leukot Essent Fatty Acids 81: 159-164. https://doi.org/10.1016/j.plefa.2009.06.006

Koletzko B, Sauerwald T, Demmelmair H, Herzog M, von Schenck U, Böhles H, Wendel U, Seidel J (2007) Dietary long-chain polyunsaturated fatty acid supplementation in infants with phenylketonuria: a randomized controlled trial. J Inherit Metab Dis 30: 326-332. https:// doi.org/10.1007/s10545-007-0491-4

Lage S, Bueno M, Andrade F, Prieto JA, Delgado C, Legarda M, Sanjurjo P, Aldámiz-Echevarría LJ (2010) Fatty acid profile in patients with phenylketonuria and its relationship with bone mineral density. J Inherit Metab Dis 33: S363-371. https://doi.org/10.1007/s10545010-9189-0

Lohner S, Fekete K, Decsi T (2013) Lower n-3 long-chain polyunsaturated fatty acid values in patients with phenylketonuria: a systematic review and meta-analysis. Nutr Res 33: 513-520. https://doi. org/10.1016/j.nutres.2013.05.003

Moore SA, Hurt E, Yoder E, Sprecher H, Spector AA (1995) Docosahexaenoic acid synthesis in human skin fibroblasts involves peroxisomal retroconversion of tetracosahexaenoic acid. J Lipid Res 36: 2433-2443

Moseley K, Koch R, Moser AB (2002) Lipid status and long-chain polyunsaturated fatty acid concentrations in adults and adolescents with phenylketonuria on phenylalanine-restricted diet. J Inherit Metab Dis 25: 56-64

Schindeler S, Ghosh-Jerath S, Thompson S, Rocca A, Joy P, Kemp A, Rae C, Green K, Wilcken B, Christodoulou J (2007) The effects of large neutral amino acid supplements in PKU: an MRS and neuropsychological study. Mol Genet Metab 91: 48-54. https://doi. org/10.1016/j.ymgme.2007.02.002

Schuck PF, Malgarin F, Henrique Cararo J, Cardoso F, Luiz Streck E, Costa Ferreira G (2015) Phenylketonuria pathophysiology: on the role of metabolic alterations. Aging Dis 6: 390-399. https://doi. org/10.14336/AD.2015.0827 
Scriver C, Beaudet A, Sly W, Valle D (2001) The Metabolic and Molecular Bases of Inherited Disease, 8th edn. ed. McGraw Hill

Shefer S, Tint GS, Jean-Guillaume D, Daikhin E, Kendler A, Nguyen LB, Yudkoff M, Dyer CA (2000) Is there a relationship between 3-hydroxy-3-methylglutaryl coenzyme a reductase activity and forebrain pathology in the PKU mouse? J Neurosci Res 61: 549-563

Singh RH, Cunningham AC, Mofidi S, Douglas TD, Frazier DM, Hook DG, Jeffers L, McCune H, Moseley KD, Ogata B, Pendyal S, Skrabal J, Splett PL, Stembridge A, Wessel A, Rohr F (2016) Updated, web-based nutrition management guideline for PKU: An evidence and consensus based approach. Mol Genet Metab 118: 72-83. https://doi.org/10.1016/j.ymgme.2016.04.008 van Gool CJ, van Houwelingen AC, Hornstra (2000) The essential fatty acid status in phenylketonuria patients under treatment. $J$ Nutr Biochem 11: 543-547

van Wegberg AMJ, MacDonald A, Ahring $\mathrm{K}$, Bélanger-Quintana A, Blau N, Bosch AM, Burlina A, Campistol J, Feillet F, Giżewska M, Huijbregts SC, Kearney S, Leuzzi V, Maillot F, Muntau AC, van Rijn M, Trefz F, Walter JH, van Spronsen FJ (2017) The complete European guidelines on phenylketonuria: diagnosis and treatment. Orphanet J Rare Dis 12: 162. https://doi.org/10.1186/s13023-0170685-2 